Volumetric and linear changes at dental implants following grafting with volume-stable three-dimensional collagen matrices or autogenous connective tissue grafts: 6-month data

Naenni, Nadja ; Bienz, Stefan P ; Benic, Goran I ; Jung, Ronald E ; Hämmerle, Christoph H F ; Thoma, Daniel S

DOI: https://doi.org/10.1007/s00784-017-2210-3

Posted at the Zurich Open Repository and Archive, University of Zurich

ZORA URL: https://doi.org/10.5167/uzh-142276

Journal Article

Accepted Version

Originally published at:

Naenni, Nadja; Bienz, Stefan P; Benic, Goran I; Jung, Ronald E; Hämmerle, Christoph H F; Thoma, Daniel S (2018). Volumetric and linear changes at dental implants following grafting with volume-stable three-dimensional collagen matrices or autogenous connective tissue grafts: 6-month data. Clinical Oral Investigations, 22(3):11851195.

DOI: https://doi.org/10.1007/s00784-017-2210-3 


\section{Volumetric and linear changes at dental implants following grafting with volume-stable three-dimensional collagen matrices or autogenous connective tissue grafts: 6-month data}

Nadja Naenni ${ }^{1}$, Stefan P. Bienz ${ }^{1}$, Goran I. Benic ${ }^{1}$, Ronald E. Jung ${ }^{1}$, Christoph H.F. Hämmerle ${ }^{1}$, Daniel S. Thoma ${ }^{1}$

Key words: collagen matrix, soft tissue, soft tissue augmentation, grafting, dental implants

Running title: soft tissue grafting at implants

Address for correspondence: $\quad$ PD Dr. med. dent. Daniel S. Thoma

Clinic of Fixed and Removable Prosthodontics and

Dental Material Science

Center of Dental Medicine, University of Zurich

Plattenstrasse 11

$\mathrm{CH}-8032$ Zurich, Switzerland

Phone: +41446343260

Fax: +41446344305

e-mail: daniel.thoma@zzm.uzh.ch

${ }^{1}$ Clinic for Fixed and Removable Prosthodontics and Dental Material Science, Center of Dental Medicine, University of Zurich, Zurich, Switzerland

\section{Acknowledgement and conflicts of interest}

The authors would like to express thanks to the team of Biomatech Namsa, Lyon, France for excellent support in animal care and housing. The support and expertise of Sibylle Huber, Geistlich Pharma AG, Wolhusen, Switzerland is highly acknowledged. The help of Gisela Müller, study monitor at the Clinic for Fixed and Removable Prosthodontics and Dental Material Science, University of Zurich, is highly appreciated. 


\begin{abstract}
Objectives:To test whether or not soft tissue augmentation with a volume-stable collagen matrix (VCMX) leads to similar volume gain around dental implants compared to autogenous subepithelial connective tissue graft (SCTG).
\end{abstract}

Materials and methods:In 12 adult beagle dogs, immediate implants were placed with simultaneous guided bone regeneration. After 25-45 weeks, soft tissue augmentation was randomly performed using VCMX, SCTG or a sham-operated control. Impressions were taken pre-op and post-op (tissue augmentation) and again at sacrifice after healing periods of 4,8 and 24 weeks. They were then digitized to allow for superimposition. Values of linear and volumetric changes were calculated.

Results: The median increase (pre-op to post-op) in buccal volume measured $0.92 \mathrm{~mm}$ for VCMX, $1.47 \mathrm{~mm}$ for SCTG and $0.24 \mathrm{~mm}$ for SH. The values(pre-op to sacrifice) were $0.25 \mathrm{~mm}$ for VCMX, $0.52 \mathrm{~mm}$ for SCTG and $-0.06 \mathrm{~mm}$ for group SH. The median ridge width $2 \mathrm{~mm}$ below the crest measured $-0.26 \mathrm{~mm}$ for VCMX, $0.53 \mathrm{~mm}$ for SCTG and -0.15 $\mathrm{mm}$ for $\mathrm{SH}$ (pre-op to sacrifice).

Conclusions: Volume augmentation using VCMX and SCTG resulted in an increase in ridge dimension (pre- to post-op). During the follow-up, the volume decreased in all three groups to a level close to the situation prior to surgery.

Clinical relevance: Soft tissue volume augmentation around dental implants is usually performed using the patient's own tissue. This therapy is associated with an increased morbidity due to a second surgical site. Soft tissue volume at implant sites can be augmented using VCMX and SCTG. The gain on top of the ridge appears not to be stable during the follow-up in both groups. 


\section{Introduction}

Following tooth extraction, remodeling and resorption processes are initiated, mainly including the bundle bone at the buccal aspect. These processes predominantly occur within the first weeks post extraction leading to a vast amount of volume loss especially at the buccal aspect of the ridge [1-3]. In order to compensate for the loss of volume, a number of surgical procedures may be necessary. Volume can be gained on the level of the hard tissue either with a primary bone augmentation preceding implant placement or simultaneous with the implant placement itself [4]. Often a deficiency of volume remains even after a GBR procedure has been performed [ $\underline{5}]$. Especially in highly demanding esthetic areas this may not lead to an appealing result. In order to gain additional volume a soft tissue augmentation procedure may be the therapy of choice [ㅈ]. Soft tissue augmentation procedures following implant placement are widely performed surgical interventions preceding abutment connection mainly and are reported to account for up to $43 \%$ of the final volume based on clinical data [ $]$ ]. The gold-standard for this procedure is the use of a subepithelial connective tissue graft (SCTG) harvested from the patients' palate and placed into a pocket on the buccal-facing aspect of the placed implant $[\underline{8}, \underline{9}]$. As this procedure leaves a second surgical site for the patient and healing may be impaired, it is desired to lower patient morbidity and at the same time shorten the healing phase [10]. Various soft tissue substitutes were evaluated in the past to replace autogenous tissue $[\underline{11-13}]$. Although clinical data demonstrated promising results for various substitute materials when used for gain of keratinized tissue or recession coverage, tissue augmentation in terms of volume gain cannot be achieved predictably using these collagen materials $[\underline{11}, \underline{14}, \underline{15}]$. In order to replace the harvesting of autogenous tissue, new volume-stable cross-linked collagen matrices (VCMX) were developed allowing for soft tissue volume augmentation [16]. In vitro and preclinical data showed favorable histological and volumetric results in terms of tissue integration and volume gain [17-19]. Although recent clinical data show similar volume gain when 
augmenting implant sites with SCTG or VCMX [20], long term data monitoring volume changes at implant sites are still scarce.

The aim of the present study was to evaluate linear and volumetric changes at implant sites having been augmented using VCMXs and SCTGs compared to sham-operated sites. 


\section{Material and Methods}

\section{Study Design}

The present study was designed as a controlled experimental study employing 12 adult male beagle dogs (more than 2 years old). The animals were weighing between $11 \pm 3 \mathrm{~kg}$ and were kept in a purpose-designed room for experimental animals and fed a soft diet during the entire study period. The protocol was approved by the local ethical committee of NAMSA (Lyon, France) on September 9, 2013 and conducted in accordance with the OECD Good Laboratory Practice regulations, ENV/MC/CHEM (98) 17, with the European Good Laboratory Practice regulations, 2004/10/EC Directive and with the United States Food and Drug Administration Good Laboratory Practice regulations, 21 CFR 58.

\section{Surgical interventions}

The surgical procedures and the applied medication were described in detail in a previous publication [16]. In brief, all surgical procedures were performed under general anesthesia and under sterile conditions in an operating room. Premedication included antibiotics and pain relief medication. Prior to the experiment the animals received a thorough cleansing of all teeth. Prior to the surgery, the respective hemi-mandible was disinfected using a $0.2 \%$ chlorhexidine (Cooper Pharma, Melun, France) and the region was locally anesthetized. Daily maintenance was provided until suture removal. All involved dogs and sites did not show signs of periodontal disease during the study.

\section{Extractions and immediate implant placement}

The mandibular mesial roots of the premolars (P3 \& P4) and the first molar (M1) were carefully extracted and the distal roots (P3, P4, M1) were root-canal treated. Thereafter, a two-piece immediate dental implant (Straumann BoneLevel, 3.3×8mm, Straumann, Basel, Switzerland) was placed in the area of the mesial root of P3/P4 of M1 with the implant shoulder placed at the level of the lingual bone crest (Figure 1). Intrabony 
defects around the implants were filled with demineralized bovine bone substitute (BioOss ${ }^{\circledR},(0.25-1 \mathrm{~mm})$, Geistlich Pharma AG, Wolhusen, Switzerland). A collagen membrane (Bio-Gide ${ }^{\circledR}$, Geistlich Pharma AG) was used to cover the augmented area. Primary wound closure was obtained using non-resorbable sutures (GoreTex 5-0 ${ }^{\circledR}$, Gore, Flagstaff, AZ, USA) that were removed 14 days later.

\section{Soft tissue augmentation}

After a healing period of at least 25 weeks, soft tissue augmentation surgery was performed on one side of the mandible in all dogs. Following midcrestal incisions between M1 and the mesial root of P4 and P3 and sulcular incisions around the distal root of M1, P3 and P4, split-thickness flaps were elevated, preparing a pouch on the buccal side of each implant (Figure $2 a+b$ ). The following three treatment modalities were randomly applied to the implant sites according to a predefined computer-generated randomization table.

- VCMX: volume-stable cross-linked collagen matrix made of porcine collagen (Geistlich Pharma AG), (Figure 2c)

- SCTG: autogenous subepithelial connective tissue graft, (Figure 2d)

- Control: sham-operated site with flap elevation, but no further augmentation, (Figure 2e)

The VCMX (dimensions: approximately $10 \mathrm{~mm}, 7.5 \mathrm{~mm}, 5 \mathrm{~mm}$ ) was soaked in saline and then positioned in the pouch under the elevated buccal flap and sutured to the lingual flap with a horizontal mattress suture (Dafilon ${ }^{\circledR}$ 5-0, B. Braun Melsungen AG, Melsungen, Germany). The SCTG was harvested from the palate of the same animal as described previously [18]. The fatty and glandular tissue as well as remnants of the epithelium were removed. The SCTG was then positioned in the pouch under the elevated buccal flap and folded in order to obtain dimensions similar to the VCMX. A horizontal mattress suture immobilized the SCTG connecting it to the lingual flap (Dafilon ${ }^{\circledR} 5-0$, B. Braun Melsungen AG). Compression with a sterile gauze followed by 3 to 4 single sutures (Dafilon ${ }^{\circledR} 5-0, B$. Braun Melsungen AG) were used to suture the donor 
site at the palate. At the control sites ( $\mathrm{SH}$; sham-operated) a pouch of the same size as in groups VCMX and SCTG was prepared, but no volume augmentation was performed. Subsequently, muco-periosteal releasing incisions were performed to allow for primary wound closure. The sites were sutured with one horizontal mattress and single interrupted sutures (Dafilon ${ }^{\circledR} 5-0$, B. Braun Melsungen AG, Melsungen, Germany). The dogs were put on a soft diet for the remainder of the study and sutures removed 14 days later.

The other sides of the mandibles were operated in a similar way, 29 to 45 weeks after tooth extraction and implant placement. (Fig.3).

\section{Dental impressions}

Pre- (before soft tissue augmentation) and post-operative (after soft tissue augmentation) impressions as well as impressions at the time of sacrifice were obtained from all mandibles using a polyether material (Permadyne, 3M ESPE, Rüschlikon, Schweiz). For T3, there were three different healing periods $(4,8$, and 24 weeks after soft tissue augmentation) (Fig.3). Impressions were performed using individualized trays made of a light-curing material (Megatray ${ }^{\circledR}$, Select Dental Manufacturing Company, Farmingdale, NY, USA). Master casts were poured out of dental stone (GC Fujirock ${ }^{\circledR}$ type 4, GC Corporation, Tokyo, Japan) and digitized using a dental scanner (Imetric 3D SA, Courgenay, Switzerland).

\section{Linear and volumetric analyses}

The obtained standard tessellation language files (STL-files) were then imported into a software program (SMOP, Swissmeda, Zurich, Switzerland) allowing for superimposition and calculation of linear and volumetric changes of the sites (Figure 4a). All measurements were performed by an experienced examiner unaware of the treatment groups at the University of Zurich (GLP like conditions). 


\section{Volumetric measurements - buccal}

The extension of the measured area (region of interest; ROI) was manually selected according to the size of the gap. The apico-coronal area was determined $0.5 \mathrm{~mm}$ apically from the transition between the buccal and occlusal plane and extended $4 \mathrm{~mm}$ in an apical direction (Figure $4 b+c$ ). The mesio-distal dimension was defined with a clearance of $1.5 \mathrm{~mm}$ to the mesial and distal adjacent tooth. The software then calculated the mean distance (MD, $\mathrm{mm}$ ) between two selected STL surfaces within the selected area. Thus, MD between pre- and post-op, post-op and sacrifice as well as between pre-op and sacrifice were calculated.

\section{Volumetric measurements - occlusal}

Similar measurements were performed for the occlusal aspect of the ridge. The oral and buccal area margin of the ROI was determined at a distance of $0.5 \mathrm{~mm}$ from the transition between the occlusal and the buccal/oral plane (Figure $4 b+c$ ). The mesio-distal dimension was defined again with a clearance of $1.5 \mathrm{~mm}$ towards the adjacent teeth.

\section{Linear measurements}

The absolute ridge width was measured at $2 \mathrm{~mm}$ below the zenith of the ridge. $\mathrm{A}$ transversal slice of the ridge, dividing the area of volumetric measurements into two equal parts was chosen. A longitudinal axis, determined by the mesial and distal adjacent teeth, was placed and the respective measurements were performed orthogonally at their respective height (Figure 4d). The changes in ridge width between the different time-points were calculated.

\section{Statistical analysis}

The analysis was programmed in R version 3.3.1 ( $\mathrm{R}$ Core Team (2016) R: A language and environment for statistical computing. R Foundation for Statistical Computing, Vienna, Austria. https://www.R-project.org/). Means, standard deviations, medians, quartiles and extreme values were computed for each clinical endpoint (gains over time) stratified by treatment and/or healing period. To investigate if gains over time were systematically different from 0 within treatment, a version of the two-sided Wilcoxon 
signed-rank test for clustered samples (Wilcoxon signed-rank test for clustered samples, implemented in R library, clusrank) was used to account for the repeated measures structure implied by the factor healing period. In order to control type I error within each endpoint and treatment, the significance level of $5 \%$ was divided by three to account for multiplicity (Bonferroni correction), i.e. $\mathrm{p}$ values were compared with $1.67 \%$ to ensure family-wise error rates of $5 \%$. The same strategy was used to compare gains between treatments. 


\section{Results:}

All dogs remained healthy during the entire study period. A delayed wound healing was reported after implant placement as well as after soft tissue augmentation for some sites, however these observations did not correlate with a treatment group. The results for the buccal and occlusal volumetric measurements as wells as the ridge width measurements are presented in Figure 5 with pooled healing periods.

Volumetric measurements - volume change buccal (Table 1)

The median increase due to the surgical intervention (pre-op to post-op) in buccal volume measured $0.92 \mathrm{~mm}$ for $\operatorname{VCMX}(\mathrm{Q} 1=0.57 ; \mathrm{Q} 3=1.33), 1.47 \mathrm{~mm}$ for SCTG $(\mathrm{Q} 1=$ $0.67 ; \mathrm{Q} 3=1.62)$ and $0.24 \mathrm{~mm}$ for $\mathrm{SH}(\mathrm{Q} 1=0.02 ; \mathrm{Q} 3=0.42)$. The increase was statistically significant for VCMX and SCTG $(p<0.009)$. Comparing the groups, group SH showed a statistically significantly lower increase compared to SCTG $(p=0.011)$.

Between post-op and sacrifice, all three groups showed a decrease in volume. Detailed data can be found in Table 1 for the pooled healing periods as well as for each group and the respective healing period. Summarizing the results by pooling the healing period, the reduction over time was statistically significant for all groups $(p<0.013)$. However, the differences between the groups $\operatorname{VCMX}(-0.99 \mathrm{~mm} ; \mathrm{Q} 1=-1.42 ; \mathrm{Q} 3=-0.90)$, SCTG ($0.75 \mathrm{~mm} ; \mathrm{Q} 1=-0.99 ; \mathrm{Q} 3=-0.31)$ and $\mathrm{SH}(-0.31 \mathrm{~mm} ; \mathrm{Q} 1=-0.41 ; \mathrm{Q} 3=-0.23)$ were not statistically significant $(p>0.017)$.

Between pre-op and sacrifice, thereby encompassing the entire study period, both the sham (SH) and test group (VCMX) lost a slight amount of buccal volume, which was not statistically significant $(p>0.094)$ over time, whereas SCTG showed a significant gain $(p=0.003)$. The median values for the pooled healing periods amounted $-0.25 \mathrm{~mm}(\mathrm{Q} 1=$ $-0.43 ; \mathrm{Q} 3=0.02)$ for $\operatorname{VCMX}, 0.52 \mathrm{~mm}(\mathrm{Q} 1=0.23 ; \mathrm{Q} 3=0.69)$ for SCTG and $-0.06 \mathrm{~mm}$ $(\mathrm{Q} 1=-0.20 ; \mathrm{Q} 3=-0.01)$ for group SH. SCTG differed statistically significantly from VCMX and SH $(p<0.008)$. The results for the buccal measurements with pooled healing 
periods as well as with separated healing periods for the time from pre-op until sacrifice are presented in Table 1.

Volumetric measurements - volume change occlusal (Table 2)

A median gain in vertical tissue dimension was calculated due to the surgical intervention (pre- to post-op) for all groups ranging from $0.15 \mathrm{~mm}(\mathrm{Q} 1=-0.16 ; \mathrm{Q} 3=0.45)(\mathrm{SH})$ to $0.38 \mathrm{~mm}(\mathrm{Q} 1=0.12 ; \mathrm{Q} 3=0.74)(\mathrm{SCTG})$, followed by a loss during the healing period (post-op to sacrifice) with values ranging from $-0.24 \mathrm{~mm}(\mathrm{Q} 1=-0.37 ; \mathrm{Q} 3=-0.24)$ $(\mathrm{SCTG}, 24-$ week healing period) to $-0.80 \mathrm{~mm}(\mathrm{Q} 1=-1.20 ; \mathrm{Q} 3=-0.45)(\mathrm{VCMX}, 24-$ week healing period). The loss during the healing pooled periods was statistically significant for VCMX and SH $(p<0.011)$. Between pre-op and sacrifice, all values were close to $0 \mathrm{~mm}$ ranging from $-0.20 \mathrm{~mm}(\mathrm{Q} 1=-0.49 ; \mathrm{Q} 3=0.02)$ for $\operatorname{VCMX}$ to $0.05 \mathrm{~mm}(\mathrm{Q} 1=-0.16 ; \mathrm{Q} 3$ $=0.05)$ for SCTG. There were no further significant differences for the comparisons within and between the groups. All results for the occlusal measurements with pooled healing periods as well as with separated healing periods for the time from pre-op until sacrifice are presented in Table 2.

Linear measurements - ridge width at $2 \mathrm{~mm}$ below the crest (Table 3)

The median ridge width $2 \mathrm{~mm}$ below the crest (Table 3 ) increased statistically significantly due to the surgical intervention (pre- to post-op) by $1.40 \mathrm{~mm}(\mathrm{Q} 1=1.02$; $\mathrm{Q} 3=1.97)$ for $\operatorname{VCMX}$ and by $1.44 \mathrm{~mm}(\mathrm{Q} 1=1.05 ; \mathrm{Q} 3=2.43)$ for SCTG $(\mathrm{p}<0.012)$. The increase of $\mathrm{SH} 0.26 \mathrm{~mm}(\mathrm{Q} 1=0.04 ; \mathrm{Q} 3=0.80)$ was not statistically significant, as well as the differences between the treatments.

During the further healing period (post-op to sacrifice), the ridge width decreased statistically significantly over time for $\operatorname{VCMX}(-1.78 \mathrm{~mm} ; \mathrm{Q} 1=-1.94 ; \mathrm{Q} 3=-1.50)$ and SCTG $(-1.33 \mathrm{~mm} ; \mathrm{Q} 1=-1.61 ; \mathrm{Q} 3=-0.30)(\mathrm{p}<0.012)$, but not for $\mathrm{SH}(-0.29 \mathrm{~mm} ; \mathrm{Q} 1=$ $-0.80 ; \mathrm{Q} 3=-0.17$ ) (pooled healing periods). Assessing the different healing periods descriptively, the values ranged between $-1.91 \mathrm{~mm}(\mathrm{Q} 1=-1.99 ; \mathrm{Q} 3=-1.83)(\mathrm{VCMX}$, 24-week healing period) and $-0.23 \mathrm{~mm}(\mathrm{Q} 1=-1.32 ; \mathrm{Q} 3=-0.15)(\mathrm{SCTG}, 4$-week healing period). 
Encompassing the period between pre-op and sacrifice, the pooled data amounted -0.26 $\mathrm{mm}(\mathrm{Q} 1=-0.56 ; \mathrm{Q} 3=0.35)$ for $\operatorname{VCMX}, 0.53 \mathrm{~mm}(\mathrm{Q} 1=-0.46 ; \mathrm{Q} 3=1.41)$ for SCTG and $-0.15 \mathrm{~mm}(\mathrm{Q} 1=-0.45 ; \mathrm{Q} 3=0.40)$ for $\mathrm{SH}$. There were neither statistically significant differences comparing gains for each treatment nor by comparing gains between treatments. All results for the ridge width measurements with pooled healing periods as well as with separated healing periods for the time from pre-op until sacrifice are presented in Table 3. 


\section{Discussion}

The present study revealed that i) a soft tissue augmentation surgery results in an increase in buccal and occlusal volume using VCMX and SCTG and even slightly at shamoperated control sites; ii) the majority of this volume gain (VCMX and SCTG) at the occlusal and buccal aspect is lost during the further healing period; iii) the ridge width increases due to the surgical intervention, but ongoing remodeling processes lead to minimal changes of the ridge width over time up to 6 months; iv) the applied method measuring linear and volumetric changes did not entirely assess the area that was augmented.

Mucogingival surgeries are frequently performed to correct volume deficiencies at implant sites. These procedures are indicated to increase the soft tissue thickness from an esthetic and a biologic point of view $[\underline{6}, \underline{21}]$. It has been demonstrated based on a recent systematic review that an increased soft tissue dimension at the crestal level results in a more favorable stability of the marginal bone level of dental implants [22]. At the buccal aspect, soft tissue volume augmentation is reported to account for more than $40 \%$ of the final volume at single implant sites [7] and a thickness of $2 \mathrm{~mm}$ is desired to allow for more prosthetic flexibility [23]. In the present study, the ridge contour was increased minimally at the crestal and predominantly at the buccal aspect of single-tooth gaps. Due to the surgical intervention, the ridge contour increased - highest at SCTG sites, slightly less at VCMX sites and even at sham-operated sites. It has been reported previously that by raising a flap, applying periosteal releasing incision and subsequent wound closure, the underlying tissue architecture changes at least in vitro $[\underline{24}, \underline{25}]$. This was clearly demonstrated at sham-operated sites in the present study. Soft tissue augmentation in VCMX and SCTG sites was performed using transplants of a similar dimension. This resulted in a volume increase at both the crestal and the buccal aspect. The overall increase, however, was higher at the buccal aspect and higher at SCTG sites compared to VCMX sites. The reason for the differences in the augmented ridge profile when comparing the two groups might be related to the structural characteristics of the grafts. SCTG transplants predominantly consist of dense connective tissue and in general 
cannot be compressed [26]. In contrast, VCMX being composed of a cross-linked collagen network, features to some extent elasticity and can be compressed to a certain degree clinically. One might speculate that the composition of the transplants was responsible for the differences in terms of the initial volume increase due to the surgical intervention.

During further healing, remodeling processes of soft tissue transplants and soft tissue substitutes are common and were described in previous preclinical and clinical experiments $[\underline{16}, \underline{20}, \underline{27}, \underline{28}]$. Moreover, it has also been observed that the tissues underlying the soft tissue grafts undergo remodeling processes as well [18]. This appears to affect not only soft tissues (in case of a split-flap), but also hard tissues in case the transplants are placed on top of bone $[\underline{17}, \underline{29}]$. In the present study, the transplants were placed in a split-flap keeping a certain distance to the underlying bone substitute material and the implants. Quite surprisingly, the applied GBR procedures were not as successful as expected. The histologic outcomes identified a direct contact between the soft tissue transplants and the implant surfaces. Obviously, more significant changes had undergone underneath the augmented soft tissues. This is supported by a recent systematic review demonstrating that following the placement of immediate implants, structural changes of the ridge are ongoing and can not be fully avoided irrespective of the applied treatment modality [30]. In the present study, the ridge profile even slightly decreased compared to the time prior to soft tissue grafting. The decrease in the ridge profile, however, was not only due to remodeling processes of the soft tissue grafts, but might also be related to the unsuccessful GBR procedures [31]. To some extent, the soft tissues probably compensated for missing hard tissue volume. This would explain to some part the small gain in volume after grafting procedures. Similar observations, with soft tissues compensating for missing hard tissue were made in two clinical studies $[\underline{32}, \underline{33}]$. In these two observational studies, cone-beam computed tomographies were analyzed 7 and 10 years post placement of immediate implants. In a certain number of cases, no buccal bone could radiologically be detected on the implant surfaces. Clinically, these cases were still considered to be successful, presenting only 
slight recession. Apart from remodeling processes changing the composition of the underlying tissues [34] on the hard and soft tissue level, is has also been speculated that tissues that are not subjected to functional load may undergo resorption [ $\underline{35}, \underline{36}]$. This might even be more pronounced for the VCMX than for SCTG. SCTGs, once transplanted, are encapsulated, which might lead to a delayed resorption and turnover as demonstrated by the histologic outcomes of the same study and previous preclinical data $[\underline{16}, \underline{17}]$. VCMX in contrast does not demonstrate any encapsulation, making it more prone to undergo remodeling processes. A higher shrinkage rate of collagen matrices compared to SCTGs over time has previously been reported [37]. In that particular study, 70\% (SCTG) and 99\% (collagen matrix) of the augmented volumes were lost during a 10-month healing period. The differences in composition and turnover might explain, to some extent at least, that over time, the obtained ridge dimension was even lower than prior to surgery in the present study.

The outcomes of the present study are therefore limited by a number of parameters: Immediately placed implants with GBR demonstrated continuous remodeling processes. At the day of soft tissue grafting, these remodeling processes were probably not finished and finally resulted in a decrease in ridge width and volume. Histologic data of the same study showed in many cases, implant surfaces were directly exposed to the augmented soft tissues. Little is known about the effect of placing soft tissue transplants directly onto exposed implant surfaces, even though, in case of peri-implant disease this has been proposed as a treatment strategy [38]. Moreover, not all sites could be included for measurements due to a lack of keratinized tissue or mucogingival junctions being displaced to the coronal aspect of the ridge due to limitations of the applied method. Keeping this in mind, the observed structural changes of the ridge might not be solely attributed to the soft tissue grafting procedures and the subsequent remodeling processes of the soft tissues. In addition, one of the major short-comings observed in the present study when compared to the previously published histologic outcomes, was that the augmented area could only partially be assessed by the applied technique. In the previously published paper on the histological outcomes [16], the whole length of the 
implants and the respective soft tissue could be evaluated up to $7.5 \mathrm{~mm}$ below the implant shoulder. In contrast, volumetric outcomes can only be assessed within the keratinized tissue, therefore not extending more than $4 \mathrm{~mm}$ more apical than the mucogingival junction and thereby only partially including the tissues on the buccal aspect of the implant. In the above mentioned paper, soft tissue augmentation was obtained at a ridge level 1 or more millimeters below the bone crest. Clinically during implant placement and later during soft tissue grafting, the augmentation of the ridge resulted in a transposition of the mucogingival junction (MGJ) towards the lingual side, shifting the MGJ even more coronal. Since, and in order to obtain reliable data, keratinized tissue needs to be present, linear and volumetric measurements could only be performed at a level more coronal to the MGJ. This resulted in a method assessing linear and volumetric changes at a level more coronal (predominantly on top of the bone crest) than where soft tissue grafting had been performed (predominantly located on the buccal side below the crest level), and did not only reflect the effect of the soft tissue augmentation procedures but rather the effect of flap preparation. Considering these limitations, the applied technique might not be ideal to assess linear and volumetric changes of the ridge using the present animal model for soft tissue grafting procedures. Nevertheless, the study clearly showed that soft tissues can not be augmented vertically. Results from the histomorphometric evaluation in the latter study showed that horizontal augmentation was obtained at a level more than $3 \mathrm{~mm}$ below the zenith of the ridge only. 


\section{Conclusion}

Soft tissue volume augmentation using VCMX and SCTG resulted in an increase in ridge dimension due to the surgical intervention. During the follow-up, the obtained gain in a vertical and horizontal dimension, predominantly located on top of the ridge crest, decreased in all groups to a level close to the situation prior to surgery. Horizontal ridge augmentation can be expected more apical than $3 \mathrm{~mm}$ below the zenith of the ridge. These changes could, however, not be assessed using the applied method.

\section{Compliance with Ethical Standards}

Conflict of Interest: Nadja Naenni declares that she has no conflict of interest. Stefan P. Bienz declares that he has no conflict of interest. Goran I. Benic declares that he has no conflict of interest. Ronald E. Jung declares that he has no conflict of interest. Christoph H.F. Hämmerle declares that he has no conflict of interest. Daniel S. Thoma declares that he has no conflict of interest.

Funding: The study was supported by a research grant of Geistlich Pharma AG, Wolhusen, Switzerland.

Ethical approval: All applicable international, national, and/or institutional guidelines for the care and use of animals were followed.

Informed consent: For this type of study, formal consent is not required 


\section{References}

[1] Cardaropoli G, Araujo M and Lindhe J (2003) Dynamics of bone tissue formation in tooth extraction sites. An experimental study in dogs. J Clin Periodontol 30:809-18. [2] Araujo MG, Sukekava F, Wennstrom JL and Lindhe J (2005) Ridge alterations following implant placement in fresh extraction sockets: an experimental study in the dog. J Clin Periodontol 32:645-52. doi: 10.1111/j.1600-051X.2005.00726.x [3] Schropp L, Wenzel A, Kostopoulos L and Karring T (2003) Bone healing and soft tissue contour changes following single-tooth extraction: a clinical and radiographic 12month prospective study. Int J Periodontics Restorative Dent 23:313-23.

[4] Christensen DK, Karoussis IK, Joss A, Hammerle CH and Lang NP (2003) Simultaneous or staged installation with guided bone augmentation of transmucosal titanium implants. A 3-year prospective cohort study. Clin Oral Implants Res 14:680-6. [5] Veltri M, Ekestubbe A, Abrahamsson I and Wennstrom JL (2016) Three-Dimensional buccal bone anatomy and aesthetic outcome of single dental implants replacing maxillary incisors. Clin Oral Implants Res 27:956-63. doi: 10.1111/clr.12664

[6] Thoma DS, Buranawat B, Hammerle CH, Held U and Jung RE (2014) Efficacy of soft tissue augmentation around dental implants and in partially edentulous areas: a systematic review. J Clin Periodontol 41 Suppl 15:S77-91. doi: 10.1111/jcpe.12220 [7] Schneider D, Grunder U, Ender A, Hammerle CH and Jung RE (2011) Volume gain and stability of peri-implant tissue following bone and soft tissue augmentation: 1-year results from a prospective cohort study. Clin Oral Implants Res 22:28-37. doi: 10.1111/j.1600-0501.2010.01987.x

[8] Langer B and Calagna L (1980) The subepithelial connective tissue graft. J Prosthet Dent 44:363-7.

[9] Langer B and Calagna L] (1982) The subepithelial connective tissue graft. A new approach to the enhancement of anterior cosmetics. Int J Periodontics Restorative Dent 2:22-33.

[10] Pizzo D (2002) The connective tissue graft: a comparative clinical evaluation of wound healing at the palatal donor site. A preliminary study. J Clin Periodontol 29:84854.

[11] Jepsen K, Jepsen S, Zucchelli G, Stefanini M, de Sanctis M, Baldini N, Greven B, Heinz B, Wennstrom J, Cassel B, Vignoletti F and Sanz M (2013) Treatment of gingival recession defects with a coronally advanced flap and a xenogeneic collagen matrix: a multicenter randomized clinical trial. J Clin Periodontol 40:82-9. doi: 10.1111/jcpe.12019 [12] Schmitt CM, Moest T, Lutz R, Wehrhan F, Neukam FW and Schlegel KA (2016) Longterm outcomes after vestibuloplasty with a porcine collagen matrix (Mucograft(R)) 
versus the free gingival graft: a comparative prospective clinical trial. Clin Oral Implants Res 27:e125-e133. doi: 10.1111/clr.12575

[13] Pabst AM, Happe A, Callaway A, Ziebart T, Stratul SI, Ackermann M, Konerding MA, Willershausen B and Kasaj A (2014) In vitro and in vivo characterization of porcine acellular dermal matrix for gingival augmentation procedures. J Periodontal Res 49:37181. doi: $10.1111 /$ jre.12115

[14] Wei PC, Laurell L, Geivelis M, Lingen MW and Maddalozzo D (2000) Acellular dermal matrix allografts to achieve increased attached gingiva. Part 1. A clinical study. J Periodontol 71:1297-305. doi: 10.1902/jop.2000.71.8.1297

[15] Rebele SF, Zuhr O, Schneider D, Jung RE and Hurzeler MB (2014) Tunnel technique with connective tissue graft versus coronally advanced flap with enamel matrix derivative for root coverage: a RCT using 3D digital measuring methods. Part II. Volumetric studies on healing dynamics and gingival dimensions. J Clin Periodontol 41:593-603. doi: $10.1111 /$ jcpe. 12254

[16] Thoma DS, Naenni N, Benic GI, Hammerle CH and Jung RE (2017) Soft tissue volume augmentation at dental implant sites using a volume stable three-dimensional collagen matrix - histological outcomes of a preclinical study. J Clin Periodontol 44:185194. doi: $10.1111 /$ jcpe. 12635

[17] Thoma DS, Hammerle CHF, Cochran DL, Jones AA, Gorlach C, Uebersax L, Mathes $S$, Graf-Hausner $U$ and Jung RE (2011) Soft tissue volume augmentation by the use of collagen-based matrices in the dog mandible - a histological analysis. J Clin Periodontol 38:1063-1070. doi: 10.1111/j.1600-051X.2011.01786.x

[18] Thoma DS, Jung RE, Schneider D, Cochran DL, Ender A, Jones AA, Gorlach C, Uebersax L, Graf-Hausner U and Hammerle CHF (2010) Soft tissue volume augmentation by the use of collagen-based matrices: a volumetric analysis. J Clin Periodontol 37:659666. doi: 10.1111/j.1600-051X.2010.01581.x

[19] Mathes SH, Wohlwend L, Uebersax L, von Mentlen R, Thoma DS, Jung RE, Gorlach C and Graf-Hausner U (2010) A bioreactor test system to mimic the biological and mechanical environment of oral soft tissues and to evaluate substitutes for connective tissue grafts. Biotechnol Bioeng 107:1029-39. doi: 10.1002/bit.22893 [20] Thoma DS, Zeltner M, Hilbe M, Hammerle CH, Husler J and Jung RE (2016) Randomized controlled clinical study evaluating effectiveness and safety of a volumestable collagen matrix compared to autogenous connective tissue grafts for soft tissue augmentation at implant sites. J Clin Periodontol 43:874-85. doi: 10.1111/jcpe.12588 [21] Boardman N, Darby I and Chen S (2016) A retrospective evaluation of aesthetic outcomes for single-tooth implants in the anterior maxilla. Clin Oral Implants Res 27:443-51. doi: 10.1111/clr.12593 
[22] Akcalı A, Trullenque-Eriksson A, Sun C, Petrie A, Nibali L and Donos N (2016) What is the effect of soft tissue thickness on crestal bone loss around dental implants? A systematic review. Clin Oral Implants Res:[Epub ahead of print]. [23] Jung RE, Sailer I, Hammerle C, Attin T and Schmidlin P (2007) In vitro color changes of soft tissues caused by restorative materials. Int J Periodontics Restorative Dent 27:251.

[24] Mir-Mari J, Benic GI, Valmaseda-Castellon E, Hammerle CH and Jung RE (2016) Influence of wound closure on the volume stability of particulate and non-particulate GBR materials: an in vitro cone-beam computed tomographic examination. Part II. Clin Oral Implants Res:[Epub ahead of print]. doi: 10.1111/clr.12845

[25] Mir-Mari J, Wui H, Jung RE, Hammerle CH and Benic GI (2016) Influence of blinded wound closure on the volume stability of different GBR materials: an in vitro cone-beam computed tomographic examination. Clin Oral Implants Res 27:258-65. doi:

$10.1111 /$ clr. 12590

[26] Harris RJ (2003) Histologic evaluation of connective tissue grafts in humans. Int J Periodontics Restorative Dent 23:575-83.

[27] Studer SP, Lehner C, Bucher A and Scharer P (2000) Soft tissue correction of a single-tooth pontic space: a comparative quantitative volume assessment. J Prosthet Dent 83:402-11.

[28] Rotenberg SA and Tatakis DN (2014) Dimensional changes during early healing after a subepithelial connective tissue graft procedure. J Periodontol 85:884-9. doi: 10.1902/jop.2013.130478

[29] Kolerman R, Nissan J, Rahmanov A, Zenziper E, Slutzkey S and Tal H (2016) Radiological and Biological Assessment of Immediately Restored Anterior Maxillary Implants Combined with GBR and Free Connective Tissue Graft. Clin Implant Dent Relat Res 18:1142-1152. doi: 10.1111/cid.12417

[30] Clementini M, Tiravia L, De Risi V, Vittorini Orgeas G, Mannocci A and de Sanctis M (2015) Dimensional changes after immediate implant placement with or without simultaneous regenerative procedures: a systematic review and meta-analysis. J Clin Periodontol 42:666-77. doi: 10.1111/jcpe.12423

[31] Chen ST and Buser D (2014) Esthetic outcomes following immediate and early implant placement in the anterior maxilla--a systematic review. Int J Oral Maxillofac Implants 29 Suppl:186-215. doi: 10.11607/jomi.2014suppl.g3.3

[32] Benic GI, Mokti M, Chen CJ, Weber HP, Hämmerle CH and Gallucci GO (2012) Dimensions of buccal bone and mucosa at immediately placed implants after 7 years: a clinical and cone beam computed tomography study. Clin Oral Implants Res 23:560-566. [33] Kuchler U, Chappuis V, Gruber R, Lang NP and Salvi GE (2016) Immediate implant placement with simultaneous guided bone regeneration in the esthetic zone: 10-year clinical and radiographic outcomes. Clin Oral Implants Res 27:253-257. 
[34] Fickl S, Kebschull M, Schupbach P, Zuhr O, Schlagenhauf U and Hürzeler MB (2011) Bone loss after full-thickness and partial-thickness flap elevation. J Clin Periodontol 38:157-162.

[35] Rubin CT and Lanyon LE (1985) Regulation of bone mass by mechanical strain magnitude. Calcif Tissue Int 37:411-417.

[36] Rubin CT and Lanyon L (1984) Regulation of bone formation by applied dynamic loads. J Bone Joint Surg Am 66:397-402.

[37] Schmitt CM, Matta RE, Moest T, Humann J, Gammel L, Neukam FW and Schlegel KA (2016) Soft tissue volume alterations after connective tissue grafting at teeth: the subepithelial autologous connective tissue graft versus a porcine collagen matrix - a preclinical volumetric analysis. J Clin Periodontol 43:609-17. doi: 10.1111/jcpe.12547 [38] Schwarz F, Sahm N and Becker ] (2014) Combined surgical therapy of advanced peri-implantitis lesions with concomitant soft tissue volume augmentation. A case series. Clin Oral Implants Res 25:132-6. doi: 10.1111/clr.12103 


\section{Figure Legends}

Figure 1

Clinical procedure with extraction of the mesial roots of P3, P4, M1, root canal treatment of the distal roots and subsequent implant placement with GBR procedure using bone substitute material and resorbable membranes.

Figure 2

Soft tissue augmentation procedure. Pictures show the occlusal and buccal situation before the augmentation (2a) and after wound closure ( $2 b)$. The three groups are shown in (2c) VCMX; (2d) SCTG; (2e) SH. Note the lingual suture in groups VCMX and SCTG to fixate the graft to the lingual.

$\mathrm{VCMX}=$ volume stable collagen matrix (at its original size of $15 \mathrm{~mm} / 20 \mathrm{~mm} / 6 \mathrm{~mm}$ );

$\mathrm{SCTG}=$ subepithelial connective tissue graft; $\mathrm{SH}=$ sham operated.

Figure 3

Time line of surgical interventions and impression taking.

Figure 4

Superimposition of the STL-files at the different time points (pre-op; post-op; sacrifice) (4a).

The region of interest (ROI) on the buccal and occlusal are depicted in blue in the overview (4b) and in orange in the cross-section view (4c). The perpendicular slice was used for measuring the ridge width at $2 \mathrm{~mm}$ below the crest $(4 \mathrm{~d})$. yellow =pre-operative; green = post-operative; grey =sacrifice. 
Figure 5

Boxplots representing the buccal and occlusal volumetric measurements as well as ridge width (RW-2) measurements $2 \mathrm{~mm}$ below the crest between all evaluated time-points (pre-operative, post-operative, sacrifice). The different healing periods are pooled and statistically significant differences $(p<0.0167)$ are marked with $*$.

Table 1

Buccal measurements with pooled healing periods as well as with separated healing periods for the time between pre-op until sacrifice.

VCMX=volume stable collagen matrix; SCTG=subepithelial connective tissue graft;

$\mathrm{SH}=$ sham site; $\mathrm{N}=$ number; $\mathrm{SD}=$ standard deviation; Min=minimum; Max=maximum; Q1=first quartile; $Q 3=$ third quartile.

Table 2

Occlusal measurements with pooled healing periods as well as with separated healing periods for the time between pre-op until sacrifice.

VCMX=volume stable collagen matrix; SCTG=subepithelial connective tissue graft;

$\mathrm{SH}=$ sham site; $\mathrm{N}=$ number; $\mathrm{SD}=$ standard deviation; Min=minimum; Max=maximum; Q1=first quartile; Q3=third quartile.

\section{Table 3}

Ridge width measurements with pooled healing periods as well as with separated healing periods for the time between pre-op until sacrifice.

VCMX=volume stable collagen matrix; SCTG=subepithelial connective tissue graft;

$\mathrm{SH}=$ sham site; $\mathrm{N}=$ number; $\mathrm{SD}=$ standard deviation; $M i n=$ minimum; Max=maximum;

Q1=first quartile; $\mathrm{Q} 3=$ third quartile. 